OmniaScience

Journal of Technology and Science Education

JOTSE, 2017 - 7(3): 274-290 - Online ISSN: 2013-6374 - Print ISSN: 2014-5349

https://doi.org/10.3926/jotse.175

\title{
PROBLEM DEFINITION AS A STIMULUS TO THE CREATIVE PROCESS: ANALYSIS OF A CLASSROOM EXERCISE
}

\author{
Renato Vizioli iD, Paulo Carlos Kaminski ii \\ Escola Politécnica da Universidade de São Paulo (Brazil) \\ rvizioli@usp.br, pckamins@usp.br
}

Received June 2015

Accepted March 2017

\begin{abstract}
Dealing with problem-solving has been a growing challenge in teaching engineering and over the career of these professionals. To increase the ability to understand a problem and consequently improve the quality of the solutions, an exercise was proposed to students of an MBA program, and they have experienced some challenges on interpreting briefing and procedures, to improve creativity and ability on solving problems. The implicit goal was to deal with the understanding of procedures to perform activities in a company and the exercise showed different ways of communicating a scenario and, consequently, different reactions depending upon the briefing. Preliminary results of the exercise indicated that the higher the degree of uncertainty on the problem definition or on an activity description, the more often association is attempted through individual repertoire, covering more varied options. In the case of a tight briefing, the creative effort appears to be overlapped by the execution of simple operations, resulting on a deviation from the required goal. Through a brief theoretical framework, this essay intends to validate these perceptions and increase the use of techniques that improve creative and problem-solving capacity in product design and development.
\end{abstract}

Keywords - Creativity; Problem definition, Design, Briefing. 


\section{Introduction}

As society deals with more complex problems since a long time ago, to be precise on its interpretation and innovative in its solutions became one of the greatest challenges of most varied professionals. Nezu and D'Zurilla (1981) state that a good approach on their proposed 4 initial stages on problem definition (1-clear description of all available facts; 2-identification of relevant and objective facts; 3 - goals definition; and 4 -explanation of why the situation is considered problematic) has a significant importance on the efficacy of the stages that follow in the process of generating alternatives, decision making and verification of proposed solutions.

In order to introduce the concept of problem solving to students in an MBA program ("Corporate Information Management" course, PECE's MBA in Product and Service Management and Engineering (Escola Politécnica da USP), April 2015 and April 2016), an exercise focused on interpreting procedures or demands was designed to demonstrate how the capacity to solve problems or perform activities may change based on the context.

Although this kind of exercise has been applied in a different format in other years-basically defining one single target and providing different ways to reach it-, after some literature review particularly regarding creativity paths, this exercise was proposed. The basic idea, according to the seven steps outlined by Sternberg and Sternberg (2011) for problem solving (Figure 1), is to intervene during the problem identification and definition steps in order to allow later steps, which are more prone to iteration, to be more open and less limiting.

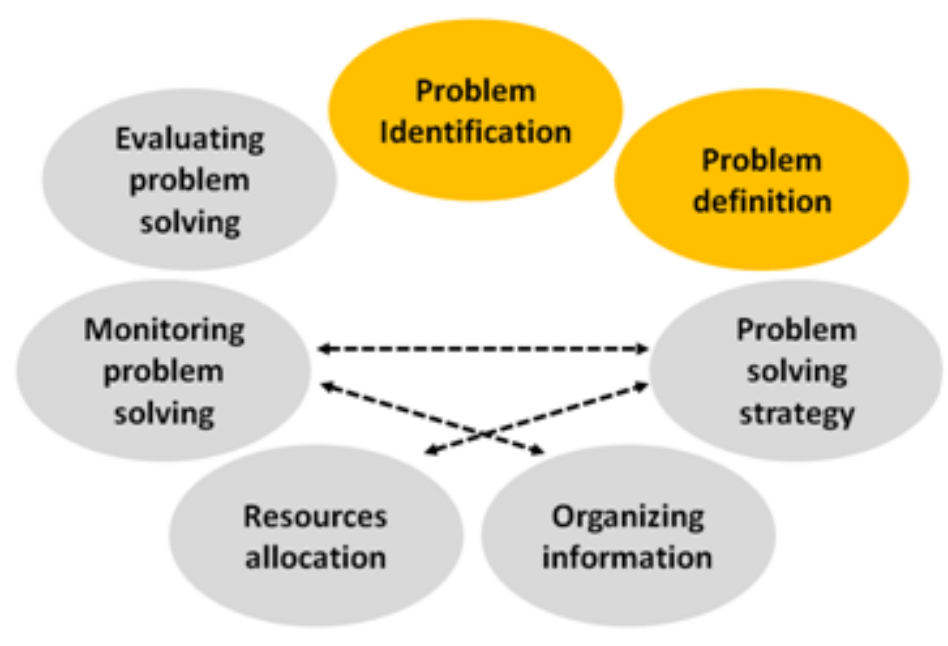

Figure 1. Emphasis on the first 2 steps of solving a problem (orange)

(Adapted from Sternberg \& Sternberg, 2011) 
On the identification phase, signals from environment must be detected, either by some kind of report or control device, but, these are pre-established ways, designed to deal more with incidents rather than with problems, which are in the root cause of the incidents. Most of times, the problem definition, to the students, is linked to some kind of predefined solution, based on the incident resolution model, and this is a major reason for them not to explore the root cause or some creative opportunity.

It's important to enlarge the boundaries of a problem and to understand it as a whole, because, during the course, and along their professional careers, students must know how to identify a problem in a corporate context and extract opportunities for effective improvement, and not only to perform mere corrective actions.

The main idea of this article is therefore the analysis of some mechanisms that can be used to deal with complex problems, generating more creative solutions that exploit individual resources underutilized, through a very simple activity in the classroom that allows approaching a broad mental repertoire. Although the study of similar cases can be found in literature dealing with each one of the proposed exercises, this paper tackles a comparative analysis on all of the three situations.

Methodologically, the article is structured with the presentation of the proposed exercise in item 2 , followed by a preliminary analysis of the results and, in item 3, a theoretical revision on how to approach a problem, taking into account the practical results.

In Item 4, some tools are proposed to facilitate-according to the analysis-a broader understanding of a problem and more creative ways to the solutions, and finally, in item 5 , a taxonomy is presented to better understand which tool should be used in each case.

\section{Application of the exercise in the classroom}

The introductory exercise involved 60 students who received three blank sheets of paper and a pencil. The exercise was divided into three parts, each lasting 5 minutes structured as follows:

- For the first part, the students were asked to draw something from nature;

- for the second part, they were asked to draw a mutamba (almost unknown tropical Brazilian fruit); 
- and finally, they were given the following instruction: "Draw a square $10 \mathrm{~cm}$ on each side on an infinite horizontal line, another square $3 \mathrm{~cm}$ on each side with its lower left corner on the midway point of the first square's diagonal and an isosceles triangle with a $12 \mathrm{~cm}$ base (parallel to the horizontal line) and $3 \mathrm{~cm}$ in height such that the midway point of its base coincides with the midway point of the top side of the first square."

In the first two parts, the idea was to keep the subject open-ended. In the case of nature, basically anything could be drawn (except supernatural things) and, in the case of the mutamba, even though it is a very distinct fruit, the subject was more open-ended and required the students to resort to a creative repertoire based on phonetic and regional cultural elements as the fruit is not known in the region (São Paulo)—and no further research was allowed.

In the third part, the idea was not to encourage creativity but, rather, to be as close-ended as possible, procedurally and operationally, and to reproduce an already defined solution.

\subsection{Preliminary result analysis}

In the first case (drawing something from nature), 55 drawings (out of 60) were of trees. In other words, even with a broad subject, the tendency was to use the most obvious reference, i.e. they intuitively substituted a part (a tree representing nature) for the whole.

In the second case, the request for a mutamba yielded different drawings ranging from canoes to percussion instruments. One student drew a generic fruit, and only two students did draw a mutamba (because they knew the fruit). This part of the exercise took longer to complete, which indicates a more elaborate search for references.

In the third case, the tight briefing, half of the drawings depicted a house, as expected. The other half consisted simply of geometric shapes. The drawing is a simple one but no final outcome was specified, so the students had some difficulty in completing the task and many failed to follow the instructions, making typical mistakes such as positioning the window in the center of the figure or placing the roof upside down, as shown in Figure 2. Regarding the "infinite" line, it was easily understood as a base line to the drawing. 


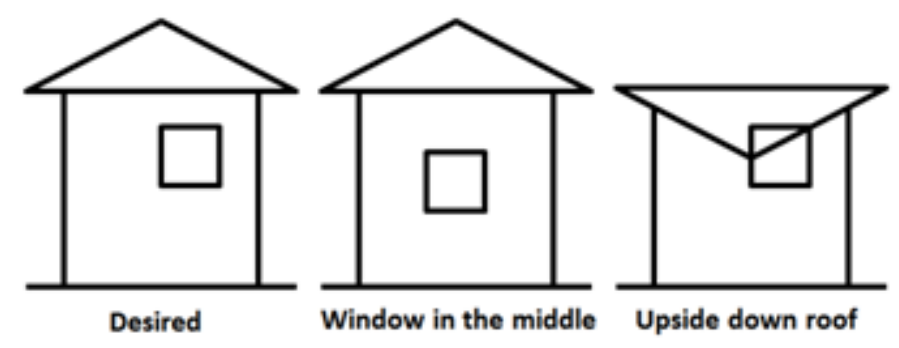

Figure 2. Typical representations for part 3 of the exercise

\section{Theoretical analysis of the results}

In this item, some theoretical background is confronted with the results of the experiment, to better understand how to use practical exercises to promote better results on the problem-solving process.

An initial analysis explores the role of so-called expertise, or experience, in problem solvingsimilarly to what a designer does in a briefing. The greater the person's experience, the more specialized the answer. Conceptual design, or that which goes beyond the trivial (Paton \& Dorst, 2011), is normally associated with higher levels of knowledge, whereas less experienced designers draw on scant empirical evidence. The use of conceptual analyses based on reframing typically produces more original (but not necessarily better) solutions. Apparently, when the framing of a problem is more open, the tendency toward reframing becomes a necessity.

For Paton and Dorst (2011) there are two distinct ways to reframe or create conceptual scenarios: as a product of knowledge or memory, through similar structures, or as a product of symbolic social structures. Through this lens, it becomes clear that the choices made in the mutamba exercise were driven by a search for cultural references after the problem is reframed around a word that is apparently indigenous, for example.

Similarly, in an exercise proposed to design students (Reyes, 2012) at Unisinos (a university in the south of Brazil), to understand the reality of a problem by developing project rationales, the first task was to discuss the concept of systems of objects and, based on this discussion, to undertake design activities. A signifier without an apparent meaning was created and named "Schillon," very similarly to the case of the mutamba. 
It was then observed that the students made free associations in different directions, such as services, objects or even rituals. Then a second project was proposed, based on a concept of system or family named "Schillen," which prompted the students to seek direct connections with the previous project, the "Schillon", although there were no connections proposed besides the phonetic similarity.

According to Deborah Tannen (1986 apud Paton \& Dorst, 2011), knowledge structure schemes and interactive scenarios are useful in countering duality in the understanding of conceptualizations. Knowledge structure schemes are based on expectations created by prior experiences with objects, events, and patterns, while interactive models orderly define what is to be done, through dialogues, as well as what activities are being undertaken and how the presenter introduces them. This is explained by Donald Schön (1996), who works with reflective practice: in his view, conceptualization presents a specific perception of a framed situation, combined with the adopted terminology and a rationalization that allows certain actions to be carried out.

Reframing through model building allows the problem to be reviewed and the briefing to be improved. However, it is important to understand that there is a point when the search must stop and a solution must be finalized, even if scenarios may change, and not necessarily because of time or resource limitations. Rather, this decision is based on a reflection regarding the moment after which it is no longer useful to continue to explore a problem.

Therefore, the briefing itself may be understood as a part of the creative process, as it emerges from the interaction between users and designers (in a broad sense). In understanding a problem, there is bias on both sides as they act as designers. Certain aspects may drive creation during the briefing, such as the definition of an objective or "final state," the inclusion of required or indispensable characteristics (conditions), a scope or coverage, and a threshold (financial, resource) value. As for instance, when developing a product and/or service, the user's and the designer's models must have enough areas of overlaping for the briefing to be considered valid.

In the research presented by Paton and Dorst (2011), designers responded that the briefing is a process of negotiation with the user, establishing a shared vision of how the development should proceed and the expectations as to its outcomes. Most of the time, the briefing does not end as development starts, but continues through the entire cycle until launch and in subsequent reevaluations. This clearly demonstrates that new perspectives on a problem emerge or are clarified during development and may be addressed before a solution is identified. Therefore, it is 
important to include a period of interaction in the proposed exercise, with changes made to the problem as it is solved, in order to verify an answer before and after the interference.

In some cases, briefings with an excessively technical focus discourage reframing and end up limiting the solutions. This becomes clear in the third stage of the proposed exercise. Similarly, when the user becomes a facilitator with a preconceived solution, the designer's actions become restricted. This kind of briefing appears in the earliest product development processes (Asimow, 1962; French, 1985) while in more recent models, the problem definition is included in the initial phases of the process (Clark \& Wheelwright, 1993; Ulrich \& Eppinger, 2012), showing the recognition of the importance of the problem discussion along the process. On the other hand, the designer is often seen (Paton \& Dorst, 2011) as someone with recognized artistic expertise, who can imprint a "brand" on an idea previously formulated by the user.

And, finally, a collaboration in which both parties understand that neither has all the knowledge required to identify possible solutions seems to be the most interesting way of approaching a briefing, as it allows the problem to be continuously reframed during the entire process in order to keep it always consistent with the stated objectives.

Through the use of techniques that include metaphors, analogies, conjectures, and contextual engagement, designers (but also users in collaborative situations) try to recontextualize the briefing. In one of the cases presented by Paton and Dorst (2011), the designer used abstractions of the problem, but with an imperceptible conceptual connection, making it easy for the user to identify unexplored areas in the briefing as no "emotional" link was established. The authors offer a summary (Figure 3) of the elements that broaden the view of a problem as metaphors, conjectures, and contexts and facilitate the creation of a model that seeks to solve the problem.

According to Christiaans (1992), in his analysis about product development strategies, "the data suggest that the more time a subject spent in defining and understanding the problem, and consequently using their own frame of reference in forming conceptual structures, the better able he/she was to achieve a creative result" (pp 136). Defining and modeling the design problem is a key activity in the quest for creativity. 


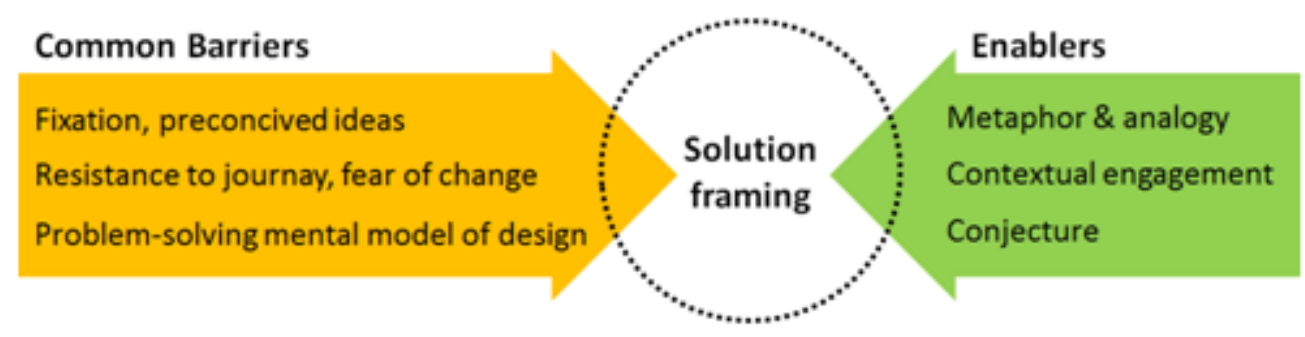

Figure 3. Barriers and enablers to reframing during briefing (Adapted from Paton \& Dorst, 2011)

In an experiment reported by Dorst and Cross (2001), related to the development of a trash bin for railroad cars in the Netherlands, participants logged their progress during their allotted time. The reports make it clear that the most creative solutions were also those in which the dialogue between the designer and the user occurred up until the end of the development, with problem identification and resolution running as parallel activities, as shown in Figure 4. In the proposed exercise, while in the third phase (the house), there is no space for reflection along the resolution, in the mutamba's phase, this happens until the end of the resolution, even if only the student by himself. Maybe, if this phase were performed in groups, this kind of dialogue and parallel activities would arise naturally.

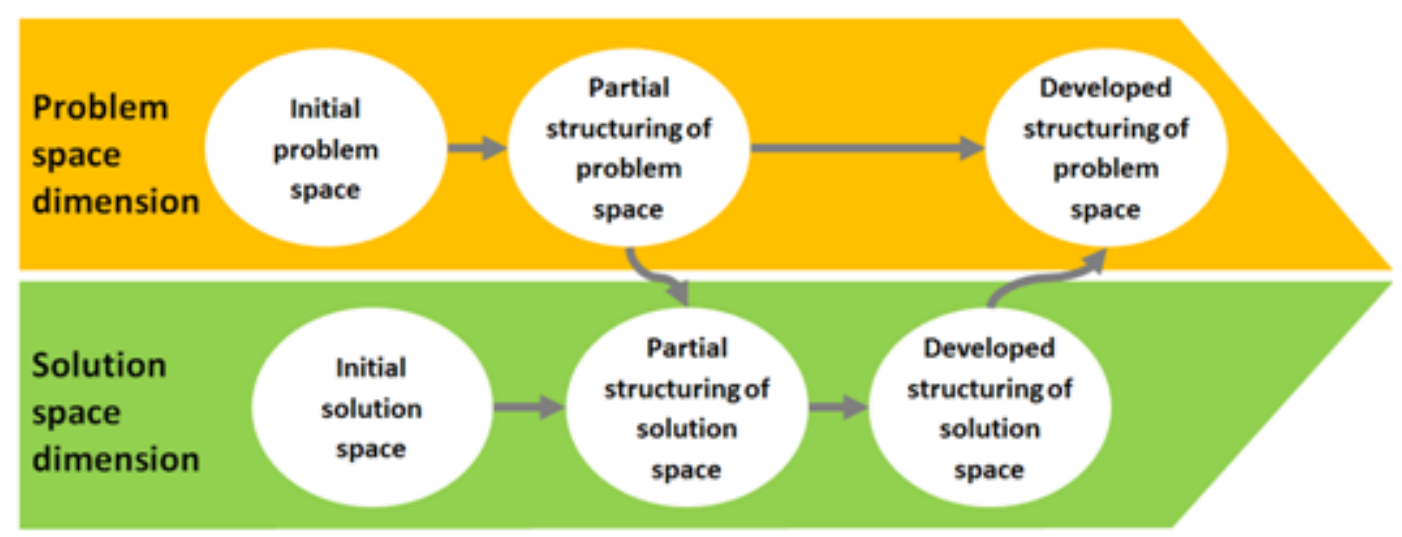

Figure 4. Interspersed dimensions for problem and solution (Adapted from Dorst \& Cross, 2001)

Both Dorst and Cross (2001), in their analysis of co-evolution, and Paton and Dorst (2011), in their vision of a joint development of a briefing, refer to the concept of a spiral in product 
development. The classical example is the development of a complex ship (Evans, 1959), which is extended to generic product development in Kaminski (2000). In this case, interaction occurs up to the end of development, and the notion of evolution over time becomes clear, as well as the interdependence among successive phases.

\section{Tools for dealing with complex problems}

Creativity involves the production of elegant, original, and high-quality solutions for complex, new, poorly defined, and ill-structured problems (Munford, Medeiros \& Partlow, 2012). In a study cited as an example by these authors, it was observed that, in a briefing presentation-an exercise in which several letters with information were distributed to students-, those who received information considered to be key points or anomalies produced more creative solutions. In another study, by Osburn and Munford (2006), high-school students who received briefings related to penetration capacity and planning produced more creative outcomes. After reviewing numerous studies, the authors concluded that briefings that stimulate disruption lead to a more productive search for information. In addition, setting objectives or establishing conditions is useful in defining the problem.

The definition of a problem (Dorst \& Dijkhuis, 1995) is supposedly stable and defines a "solution space" to be explored. Dorst \& Dijkhuis (1995), quoting Donald Schön, state that any design problem is unique and the designer's qualities boil down to determining how each particular problem should be addressed. In order to describe how to fundamentally deal with a unique problem, Schön proposes an alternative epistemology of practice, summarized by Dorst \& Dijkhuis (1995), based on a constructionist view of human perception and thought process, as showed in Table 1.

\begin{tabular}{|l|l|l|}
\cline { 2 - 3 } \multicolumn{1}{c|}{} & Rational problem solving & Reflection in action \\
\hline Designer & Processes information (objective reality) & Constructs own reality \\
\hline Design problem & Ill-defined, unstructured & Essentially unique \\
\hline Design process & Rational search process & Reflective conversation \\
\hline Design knowledge & $\begin{array}{l}\text { Knowledge of design procedures and } \\
\text { scientific rules }\end{array}$ & $\begin{array}{l}\text { Mastery of design: when to apply which } \\
\text { procedure / part of knowledge }\end{array}$ \\
\hline Example / model & Theory of optimization, natural sciences & Art / social sciences \\
\hline
\end{tabular}

Table 1. Paradigms of rational problem solving and reflection in action (Based on Dorst \& Dijkhuis, 1995) 
According to Neve (2012), society is highly focused on immaterial concepts such as ideas, knowhow, skills, and experience. Human capital is one of the most important resources in organizations and the capability to manage it becomes a major competitive advantage. The author cites the example of Skanska, a global construction company headquartered in Sweden. Neve states that, formulating questions correctly promotes learning.

For example, in cognitive psychotherapy, how the therapist asks questions to the patient is key. The assumption is that correct questions help individuals pinpoint their knowledge much more effectively (Perris, 1989, apud Neve, 2012), whereas improperly formulated questions obstruct thought. Therefore, from a therapy point of view, rationality is apparently a priority, trumping creativity, as it leads to self-knowledge and not to digression.

A simple rule derived from this case is the use of neutral questions instead of words loaded with values, such as "the most, the largest, the main." This implies that questions containing, for example, "how, when, and in what way" are appropriate for use, and questions that directly indicate "why" something is how it is are not very productive and should preferably be avoided.

Extrapolating to the field of design, a stage of knowledge based on the rational seems to make sense, followed by a search for new alternatives through creativity. Ohlsson (2012) corroborates this view and states that to solve a problem is to do something about it. In many cases, thinking of the right action is the key. The competence of an average adult encompasses hundreds, perhaps thousands of actions, so the set of actions considered during heuristic search is necessarily a small subset. The author poses the question as to which subset must be activated in the context of an unfamiliar problem. If the answer is a simple retrieval from memory, there is no reflection, and the action taken is a trivial solution to the problem. Framing a problem in an unusual manner drives reflection prior to action.

Another approach favored by Ohlsson is to define an objective rather than postulate a problem in order to avoid actions that represent simple solutions and to allow reflection on better ways to reach the objective.

Valkenburg and Dorst (1998) also tested Schön's theory of reflective practice, which is based on four activities—naming, framing, moving, and reflecting. Two groups were studied out of the nine that participated in a contest organized by Philips, and the authors observed that the designers began by giving names to the relevant problems in the proposed situation, in a way repeating frames for the problems, seeking a solution by applying the frames and, finally, 
reflecting on how the application of these frames affected the results. Reflection is a rational and conscious action that leads to the creation of new frames and the reformulation of problems, the performance of new searches or the identification of new problems. This was observed in both groups.

\section{Stimulus to creativity in design}

Techniques that stimulate ambiguity (Berg, Taatila \& Volkmann, 2012) may drive creativity in the search for solutions.

According to Berg et al. (2012) it's important to develop tolerance for ambiguity in the designer's activities when dealing with questions that are out of the ordinary or, otherwise, to avoid preconceived notions. An environment that is open to change and does not restrict initiatives merely because they deviate from norms and standards can be conducive to this.

Numerous techniques help create this type of environment, as summarized in Table 2 (Massaro, Bardy \& Pitts, 2012), based primarily on the use of metaphors (synectics) in indirect approaches, from another's point of view, as in the case of "design thinking," but also on techniques that focus more on accumulated knowledge, as in the case of TRIZ, which is based on the broad view of patents by similarities.

\begin{tabular}{|l|l|}
\hline Approaches & Description \\
\hline Creative Problem Solving & $\begin{array}{l}\text { Development of a process for solving problems with six steps: 1. Exploring the } \\
\text { vision; 2. Describing the challenge; 3. Discovering the idea; 4. Defining the } \\
\text { solution; 5. Exploring the acceptability; 6. Formulating a plan. }\end{array}$ \\
\hline Lateral Thinking & $\begin{array}{l}\text { A technique of thought and perception that leads to a development that provides } \\
\text { an indirect approach, observing the problem from different angles, as opposed to } \\
\text { the traditional mode that concentrates on a direct solution to the problem. }\end{array}$ \\
\hline Appreciative Inquiry & $\begin{array}{l}\text { A process that analyzes elements that work and those that do not work within an } \\
\text { organization. The phases are: 1. Discovery; 2. Dream; 3. Design; 4. Destiny. }\end{array}$ \\
\hline Design Thinking & $\begin{array}{l}\text { Mainly applied to re-engineering of products, this approach is characterized by: } \\
\text { 1. Understanding; 2. Observation; 3. Viewpoint; 4. Displaying; 5. Prototyping. }\end{array}$ \\
\hline Synectics & $\begin{array}{l}\text { Development of a process that encourages participants to talk in metaphors. The } \\
\text { process involves the use of analogies: Direct, Personal, and Symbolic analogies. }\end{array}$ \\
\hline Inventive Problem Solving & $\begin{array}{l}\text { Developed by the Department for Patents in the Soviet Navy and known by the } \\
\text { acronym TRIZ, this methodology is based on rational issues. Among the most } \\
\text { important phases of this methodology, which provides a detail of } 40 \text { micro- } \\
\text { activities, are: 1. Segmentation; 2. Defining local quality; 3. Exploring asymmetry; } \\
\text { 4. Testing universality. }\end{array}$ \\
\hline
\end{tabular}

Table 2. Several approaches to the creative process in the literature (Based on Kaufman \& Stenberg, 
Although most of the technics in Table 2 try to give a complete approach on the problemsolving question, what matters here are the main characteristics of each one of them, some using the divergence-convergence concept of thinking, others using rational and functional bias, but all of them using ambiguity in analyzing the problem as a key point.

Mumari (1987) proposes another interesting technique in his exercise on the exploration of a tree leaf, in which an extensive formal derivation extrapolates the initial physical form provided by nature (the thing is born out of the thing).

All techniques converge to concepts such as elimination of preconceived notions and tolerance for the unknown, the ambiguous, and, at the other extreme, excessive information or complexity.

\section{Context for applying the techniques}

These cases show that the use of specific techniques is delimited so that more pragmatic and effective solutions can be obtained. Some criteria are used (Mozota, 2003) to establish the scope of the briefing or the definition of the problem. These criteria are based on different factors, such as who is financing the development (stakeholders), moves in the market or by competitors, and environmental variables. Table 3 summarizes the preparation of a generic briefing that is presented by a company to a designer or design firm.

\begin{tabular}{|l|l|}
\hline Design Project Objective & $\begin{array}{l}\text { Specifies the required design performance with metrics related to cost reductions, } \\
\text { image improvement or sales increases. }\end{array}$ \\
\hline Company Information & $\begin{array}{l}\text { Company activities, history, size, and positioning in its corporate environment. } \\
\text { Company's operational structure, professionals working with the designer, company } \\
\text { identity, and its business image and mission. } \\
\text { Level of attractiveness of the company's industry and its business and development } \\
\text { strategy in the market. } \\
\text { Company's position in its different markets, the economic, social, and cultural } \\
\text { evolution of its market, brand positioning, price structure, market research, and life- } \\
\text { style studies. }\end{array}$ \\
\hline $\begin{array}{l}\text { Conceptual data (method of conception, level of originality, project relevance to the } \\
\text { company's overall plans). } \\
\text { Pechnical data (type of technology and materials; means of production; innovation } \\
\text { management methods; technical restrictions; definition of R\&D and design } \\
\text { attributions; and the role of suppliers and partners). } \\
\text { Commercial data (distribution, communication, and sales policy) } \\
\text { Marketing data (target public, segmentation of consumer preferences, marketing and } \\
\text { brand positioning) } \\
\text { Financial data (budget, technical and design investment, development costs) }\end{array}$ \\
\hline
\end{tabular}

Table 3. Definition of the design project briefing by a company (Summarized from Mozota, 2003) 
There are requirements that define the path to be followed in the next framing of the problem. If, through strategic or financial definitions, for example, the stated objective is to improve a particular product-focused on a particular function — and not to search for new concepts, the approach is necessarily much more focused on applying technical knowledge than creative expansion.

Clark and Wheelwright (1993) conduct an analysis of process enhancements introduced to improve products and classify them as radical innovations, new platforms or changes in existing products within this framework. Henderson and Clark (1990) use the same classification (Figure 5), listing systems and products with components and core concepts. Radical innovation involves a disruptive design whereby previously unknown concepts and needs are combined with system architectures and production or operational processes conceived specifically for the new situation.

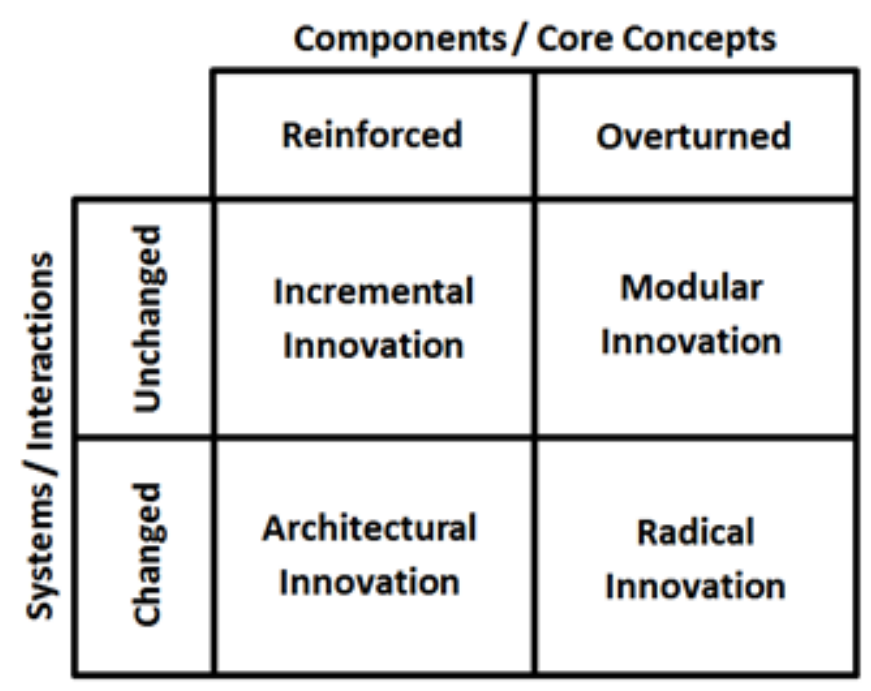

Figure 5. A framework for innovation in design

(Henderson \& Clark, 1990)

Depending on the strategic objectives, a balance can be reached between using structured knowledge, represented here by a tight briefing that is more similar to a functional specification, or attempting to expand the scope of the problem through ambiguity and tolerance for error with creative techniques and an emphasis on cognitive components and perception of the user's wishes. 
Figure 6, which is based on the classifications of Henderson and Clark (1990) and Clark and Wheelwright (1993), proposes two axes: horizontal, with functional increments (of a product or service), and vertical, in which new-and unknown - needs are met. Innovation occurs in the positive direction in both axes. However, the more ambiguous views, tolerance for error, lateral thinking or metaphors are used, the more likely the creation of new concepts that become innovations through the use of technologies that make the functions viable.

In Figure 6, the intersection of the axes represents a current situation, and the possible paths toward different types of innovation are determined by how the problem is analyzed.

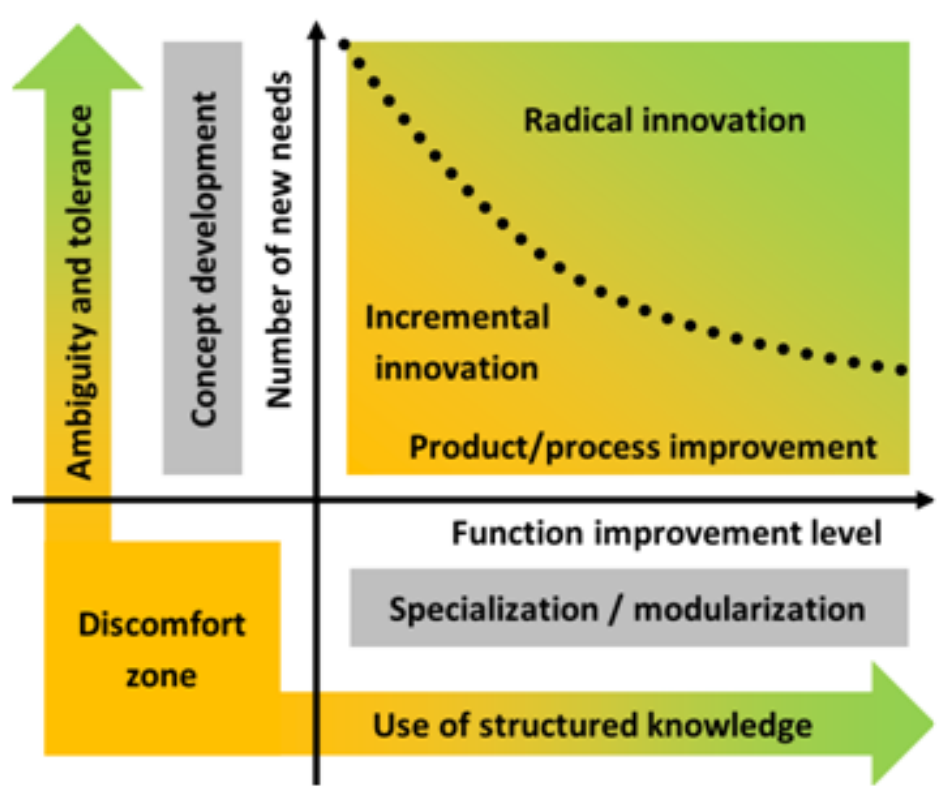

Figure 6. Approach to the problem and the objective of innovation

It seems intuitive that progression cannot occur along only one of the axes in Figure 6. This would imply a utopian view (along the vertical axis only) or static rationalism (along the horizontal axis).

The cases in the literature reviewed here empirically indicate that, above all, the objective, the holistic vision, and an intrinsic desire determine this balance. 


\section{Conclusions}

By using some relatively simple and readily available tools, a group of designers involved in a project can stimulate creativity from the outset in order to obtain a better solution to a problem.

In summary, when one avoids obvious references, by using unexpected names for the solution, for example, one encourages new paths to be sought, leading to different solutions and thus increasing the likelihood of better, more innovative outcomes.

Macro-objectives also need to be defined but these should not be restrictive and configure the solution itself. They must be holistic and contain ambiguities in order to promote more open and broader attitudes. The encouragement of tolerance makes the need to deal with complexity acceptable from the outset.

Finally, these tools must be used iteratively throughout the creative and development process as the environment changes during the project and new variables are included, which influence even the definition of objectives. The selection of one path over another, or the appropriate balance in the use of different approaches, hinges on a design strategy, the corporate environment, and a series of specific deciding factors for each context. However, one can always take advantage of opportunities to expand one way of analyzing a problem and use these simple exercises or more elaborate techniques.

\section{References}

Asimow, M. (1962). Introduction to design. NY: Prentice-Hall.

Berg, H., Taatila, V., \& Volkmann, C. (2012). Fostering creativity - a holistic framework for teaching creativity. Development and Learning in Organizations, 26(6), 5-8. https://doi.org/10.1108/14777281211272242

Clark, K.B., \& Wheelwright S.C. (1993). Managing new product and process development: Text and Cases. NY: Free Press.

Christiaans, H. (1992). Creativity in design. PhD Thesis, Delft University of Technology, Delft.

Dorst K., \& Cross, N. (2001). Creativity in the design process: Co-evolution of problem-solution. Design Studies, 22(5), 425-437. https://doi.org/10.1016/S0142-694X(01)00009-6 
Dorst, K., \& Dijkhuis, J. (1995). Comparing paradigms for describing design activity. Design Studies, 16(2), 261-274. https://doi.org/10.1016/0142-694X(94)00012-3

Evans, J.H. (1959). Basic design concepts. Journal of the American Society for Naval Engineers, 71(4), 671-678. https://doi.org/10.1111/j.1559-3584.1959.tb01836.x

French, M.J. (1985). Comceptual design for engineers. Berlin: Springer-Verlag. https://doi.org/10.1007/9783-662-11364-6

Henderson, R.M., \& Clark, K.B. (1990). Architectural innovation: The reconfiguration of existing product technologies and the failure of established firms. Administrative Science Quarterly, 35(1), 9-30. https://doi.org/10.2307/2393549

Kaminski, P.C. (2000). Desenvolvendo produtos com planejamento, criatividade e qualidade. São Paulo: Livros Técnicos e Científicos Editora.

Massaro, M., Bardy, R., \& Pitts, M. (2012). Can creativity be learned? The knowledge integration role of Management Control Systems during the creative process. In: Proceedings of the 4rd European Conference on Intellectual Capital, Arcada University of Applied Sciences Helsinki, 272-278 April 2012, Helsinki, Finland.

Mozota, B.B. (2003). Design management-using design to build brand value and corporate innovation. NY: Allworth Press.

Mumari, B. (1987). Fantasia-invenção, criatividade, imaginação na comunicação visual. Lisboa: Editorial Presença.

Munford, M.D., Medeiros, K.E., \& Partlow, P.J. (2012). Creative thinking: processes, strategies, and knowledge. The Journal of Creative Behavior, 46(1), 30-47. https://doi.org/10.1002/jocb.003

Neve, T.O. (2012). Begin with the end to solve business problems and create a competitive advantage. In: Proceedings of the 4rd European Conference on Intellectual Capital, Arcada University of Applied Sciences Helsinki, 338-344 April 2012, Helsinki, Finland.

Nezu, A., \& D'Zurilla, T.J. (1981). Effects of problem definition and formulation on the generation of alternatives in the social problem-solving process. Cognitive Therapy and Research, 5(3), 265-271. https://doi.org/10.1007/BF01193410 
Ohlsson, S. (2012). The problems with problem solving: Reflections on the rise, current status, and possible future of a cognitive research paradigm. The Journal of Problem Solving, 5(1), 101-128. https://doi.org/10.7771/1932-6246.1144

Osburn, H.K., \& Munford, M.D. (2006). Creativity and planning: training interventions to develop creative problem-solving skills. Creativity Research Journal, 18(2), 173-190.

https://doi.org/10.1207/s15326934crj1802_4

Paton, B., \& Dorst K. (2011). Briefing and reframing: A situated practice. Design Studies, 32(6), 573-587. https://doi.org/10.1016/j.destud.2011.07.002

Reyes, P. (2012). Projetando pela exterioridade do projeto. Strategic Design Research Journal, 5(2), 91-97. https://doi.org/10.4013/sdri.2012.52.05

Schön, D.A. (1996). The reflective practitioner - How professionals think in action. London: Arena.

Sternberg, R.J., \& Sternberg, K. (2011). Cognitive Psychology. Belmont: Wadswoth.

Ulrich, K., \& Eppinger, S.D. (2012). Product design and development. NY: McGraw-Hill Irwin.

Valkenburg, R., \& Dorst, K. (1998). The reflective practice of design teams. Design Studies, 19(3), 249-271. https://doi.org/10.1016/S0142-694X(98)00011-8

Published by OmniaScience (www.omniascience.com)

Journal of Technology and Science Education, 2017 (www.jotse.org)

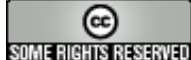

Article's contents are provided on an Attribution-Non Commercial 3.0 Creative commons license. Readers are allowed to copy, distribute and communicate article's contents, provided the author's and JOTSE journal's names are included. It must not be used for commercial purposes. To see the complete licence contents, please visit http://creativecommons.org/licenses/by-nc/3.0/es/ 